\title{
Do aggravating rhinologic symptoms at work indicate occupational exposure? A cross-sectional outpatient clinic study
}

\author{
Maija Ylivuori, ${ }_{1}^{1}$ Liisa Airaksinen, ${ }^{2}$ Harri Sintonen, ${ }^{3}$ Risto $P$ Roine,${ }^{4}$ Maija Hytönen, ${ }^{1}$ Paula Virkkula ${ }^{1}$
}

\begin{abstract}
Background: Air impurities can exacerbate or cause rhinologic diseases. However, only a few studies have assessed rhinologic patients' symptoms at work.

Objective: This study surveys the impact of work on rhinology clinic patients' quality of life in relation to work-related respiratory exposures. In addition, we surveyed patients' sick leave periods.

Methods: We recruited adult employed rhinology patients referred to the otorhinolaryngology clinic. A total of 177 patients were included. We collected data on patients' medical history, rhinologic disease-specific and generic quality of life, current or most recent job title, a description of current work, nasal symptoms, possible worked-related symptom triggers and sick leave periods during the preceding year.
\end{abstract}

Results: In total, 101 (57.1\%) patients reported exacerbated rhinologic symptoms at work and reported more severe rhinologic disease and a lower disease-specific quality of life compared to non-work-related rhinologic patients $(P=$ 0.008). A minority, $24.3 \%$ of our patients were exposed to any specific occupational respiratory sensitizer or irritant at work. The mean sick leave period due to rhinologic disease was 7.7 days per year.

Conclusions: Exposure to specific occupational sensitizers or irritants did not associate with increasing symptoms at work or quality of life amongst our patients. Most rhinology patients reported exacerbated symptoms at work. They appeared to be more symptomatic than the rest of the patients and, therefore, possibly hyperreactive to unspecific respiratory triggers at work. Rhinologic diseases caused our patients a marked burden with high work absenteeism.

Key words: Rhinology, work-related, HRQoL, SNOT-22, 15D

\footnotetext{
Author affiliations:

Department of Otorhinolaryngology - Head and Neck Surgery, Helsinki University Hospital and University of Helsinki, Helsinki, Finland

${ }^{2}$ Finnish Institute of Occupational Health, Helsinki, Finland

${ }^{3}$ Department of Public Health, University of Helsinki, Helsinki, Finland

${ }^{4}$ Group Administration, Helsinki University Hospital and University of Helsinki, Helsinki, Finland; and Department of Health and Social Management, University of Eastern Finland, Kuopio, Finland
}

\section{Corresponding author:}

Maija Ylivuori

Department of Otorhinolaryngology - Head \& Neck Surgery

Helsinki University Hospital

Kasarmikatu 11-13, Helsinki

PO Box 263, FIN-00029 HUS, Finland

E-mail: maija.ylivuori@helsinki.fi

\section{Introduction}

The most common nasal diseases at rhinologic outpatient clinic are chronic rhinosinusitis (CRS), nonallergic noninfectious rhinitis (NAR) and allergic rhinitis (AR). The prevalence of AR has been estimated to be $23 \%$ in European countries and $30 \%$ in Finland, ${ }^{1-2}$ and the prevalence of CRS has been estimated to be $10.9 \%$ in Europe. ${ }^{3}$ Air impurities can exacerbate nasal diseases. ${ }^{4-7}$ Occupational irritant exposure increases the risk of NAR and CRS. ${ }^{6,8}$ However, few studies have evaluated the possible influence of impurities in the air at work on workers experiencing different rhinologic diseases, apart from occupational rhinitis (OR) and CRS., ${ }^{4,5}$ A healthy population blue-collar (mainly manual labor) workers had been found a significantly poorer rhinitis -specific health-related quality of life (HRQoL). ${ }^{10}$ In a Swedish study, an additional risk of nasal symptoms resulted from exposure to fire fumes 
and cleaning agents and to paper or textile dust. ${ }^{8}$ Occupational exposure to solvents also appears to increase the risk of rhinitis. $^{7}$

The primary prevention of CRS and OR symptoms focuses on minimizing exposure to respiratory impurities, smoking, occupational and environmental toxins and sensitizers. ${ }^{11}$ Work-related rhinitis is often classified into work exacerbated rhinitis, where previous rhinitis is worsened at work and occupational rhinitis in which agents at work mainly cause the rhinitis. ${ }^{12}$ The occupational agents that can cause OR are categorised according to their molecular weight. High-molecular weight (HMW) sensitisers $(>10 \mathrm{kDa})$ include IgE-mediated allergens like animal and vegetable origin proteins, such as flours, mites and animal dander. Low-molecular weight (LMW) sensitisers include some chemicals, drugs and metals. In addition, various chemical toxicants can injure mucosa, but handling and use of occupational mucosal-irritating and hazardous substances at workplaces are under occupational safety limits and control.

This study assessed whether unselected rhinology clinic patients' disease exacerbates at work, whether that exacerbation is related to work-related respiratory exposures and identified the potentially relevant exposures. Symptoms at work were evaluated using the rhinologic disease-specific and general HRQoL measurement. In addition, this study examined the sick leave periods reported by patients during the preceding year. To our knowledge, the number of sick days amongst rhinology patients referred to special medical care remains unreported.

\section{Patients and Methods \\ Patients}

We invited all eligible adult ( $\geq 18$ years) employed patients referred to their first visit to the Helsinki University Hospital Department of Otorhinolaryngology because of a rhinological condition. The clinic serves as a secondary/tertiary referral center for ORL patients. As we wanted to minimize the potential impact of the season on SNOT-22 results, we collected patients at different times of the year, i.e. in May, August and November 2014 to take part in the survey. We excluded patients who had not worked or studied full-time during the preceding 6 months.

\section{Methods}

This study is a prospective, cross-sectional, questionnaire-based study amongst patients with diverse rhinologic diseases. Patients were sent a questionnaire, covering the following topics: medical history; the SNOT-22 questionnaire; a generic HRQoL questionnaire (15D); an open-ended description of their description of work tasks (during the previous 6 months), current work status, patient-evaluated exposures to dust or powdery substances, chemicals, solvents, smoke, gases or fumes, cold and hot air and stale or mouldy air at work; their current or most recent job title. In addition, we asked if any exposures were related to an increase in their nasal symptoms at work. One question ('Do you have physician-diagnosed asthma?') was added to the questionnaires during the recruitment period. From the job title, work description and patient reported types of exposures, a specialized and experienced occupational hygienist classified whether the patient was exposed to specific occupational sensitizers or irritants. According to the basic occupational hygiene safety principle the patients were assessed as exposed in uncertain cases. Patients were also asked to report their need for sick leave during the preceding year. The data of patient ICD 10 - diagnosis were collected from the electronic patient records after an outpatient visit. The primary diagnosis in our assessment was based on a disease requiring active treatment. The patients were examined at the rhinological clinic of the University Hospital and their diagnoses were based on international recommendations, e.g. CRS was based on The European Position Paper on Rhinosinusitis and Nasal Polyps 2012 guidelines $^{13}$ doctor-diagnosed allergy was based on allergy tests done previously or after the outpatient visit, non-allergic rhinitis was based on typical symptoms and exclusion of allergy. Turbinate hypertrophy was based on nasal congestion and difficulty in nasal breathing not alleviated by appropriate drug therapy, and clinical observation without significant septal deviation. Turbinate hypertrophy was diagnosed in this study if the patient was scheduled for turbinate radiofrequency ablation. Nasal septal deviation was diagnosed in patients with difficulty in nasal breathing associated with nasal septal skewness, and when the patients were scheduled for septoplasty. Objective measurements were used to aid in the assessment of structural obstruction.

SNOT-22 is a widely used rhinologic disease-specific HRQoL questionnaire, which has been validated in Finnish. ${ }^{14,15}$ Higher total SNOT-22 scores represent worse quality of life. For analysis, the SNOT-22 questionnaire can also be divided into subscales: nasal symptoms (questions 1-8), otologic/facial pain (questions 9-12), sleep (questions 13-20) and emotional subdomains (questions 21-22). ${ }^{16}$ The generic 15D questionnaire is a standardized, validated, self-administered HRQoL instrument that can be used both as a profile and as a single-index measure (http://www.15d-instrument.net/15d/), consisting of 15 dimensions. For each dimension, the respondent must choose one of five levels best describing her/his health status at that moment (best level $=1$; poorest level $=$ 5). We classified the patients' socioeconomic status using the 1989 Statistics Finland's classification (Table 1). ${ }^{17}$ Patients' work titles were categorized according to International Standard Classification of Occupations (ISCO2010) and her/his description of their work. To compare our patient sample to the entire Finnish and Uusimaa district working population, we used the 2014 Statistics Finland's Classification of Socioeconomic Groups ( $n=2217049$ and $n=722$ 266). ${ }^{18}$

The Research Ethics Board of the Helsinki University Hospital approved this study 20.1.2014. 31 (Dnro $336 / 13 / 03 / 00 / 13)$. All patients included provide their written informed consent.

\section{Statistical analysis}

All statistical analyses were performed by a professional statistician using the Student's independent samples t-test in cases where we compared the means of two groups. Where the requirement for a normal distribution was not met, the Mann-Whitney U-test was used. We considered the differences between groups as statistically significant at $P<0.05$. 
Table 1. Socioeconomic status groups. $1=$ self-employed persons (including group $1=$ farmers and group $2=$ other), $2=$ upper-level employees in administrative, managerial, professional and other related occupations, $3=$ lower-level employees in administrative and clerical occupations and $\mathbf{4}=$ manual laborers. Study Patients and Population (Finnish Labour Socioeconomic Group in 2014 in the Uusimaa district and in Finland)

\begin{tabular}{cccc}
\hline Socioeconomic group & Patients, \% & Population in Uusimaa, \% & Population in Finland, \% \\
\hline 1 & 7.0 & 8.6 & 10.8 \\
2 & 32.6 & 28.8 & 21.9 \\
4 & 39.0 & 38.3 & 37.6 \\
\hline
\end{tabular}

\section{Results}

In total, 224 patients returned completed questionnaires. We excluded three patients who were under 18 years of age and another 44 patients who had not worked during the previous 6 months. Eighty percent of the patients were in working life. Thus, our study consisted of 177 patients. We excluded one incomplete 15D questionnaire from further analysis. The total response rate of the study, $46.3 \%$, was recorded during one month (November 2014). We found no statistically significant age or gender differences between respondents (mean age, 48.6 years and $47.2 \%$ male) and non-respondents (mean age, 44.1 years and $46.0 \%$ male), respectively.

The sex distribution was roughly even (47.4\% male), whilst the mean age for all patients was 44.8 years (range, 18.5-75.1) in our sample. When compared to the Finnish labor force in 2014 in the Uusimaa district, our sample did not differ with regards to age, gender distribution or the socioeconomic status (Table 1), yet when compared to the entire Finnish labor force, the sample of patients comprised fewer manual laborers $(P=0.002)$. In addition, $27(15.3 \%)$ patients were current smokers and $92(52.0 \%)$ patients had never smoked. Asthma question was answered by 102 patients and 23 patients (22.5\%) had asthma. Doctor-diagnosed allergic rhinitis was identified in $64(36.2 \%)$ of patients. The most frequent primary diagnosis was CRS ( $\mathrm{n}=59,33 \%$ ), followed by rhinitis $(\mathrm{n}=36,20 \%)$, rhinitis with turbinate hypertrophy $(\mathrm{n}=26$, $15 \%)$ and septal deviation $(\mathrm{n}=22,12 \%)$. The mean SNOT22 and $15 \mathrm{D}$ scores amongst all the study patients were 36.2 $( \pm$ SD 17.5$)$ and $0.88( \pm$ SD 0.09$)$, amongst CRS patients 43.9 $( \pm$ SD 16.7$)$ and $0.86( \pm$ SD 0.10$)$, and amongst rhinitis patients $35.6( \pm$ SD 16.8$)$ and $0.89( \pm$ SD 0.08$)$, respectively. A total of $101(60.1 \%)$ patients reported that their rhinologic symptoms worsened at work, whilst $67(39.9 \%)$ patients mentioned that symptoms did not worsen. We identified no gender, age or socioeconomic differences between patients whose symptoms worsened at work and those whose symptoms did not. The number of asthmatics, allergy patients, or smokers did not differ between these two groups either (NS). Twenty-five and 24.8 percent of patients in these groups were exposed to work-related specific sensitizers or irritants. Since we also examined patient-reported triggers in indoor environments, $56.7 \%(n=55)$ experienced a worsening of nasal symptoms associated with nonspecific dust or powdery substances, $35.1 \%(n=34)$ associated with stale or moldy air and $20.6 \%$ $(\mathrm{n}=19)$ associated with cold air. Smoke, gases or fumes ( $\mathrm{n}$ $=16,16.5 \%)$ and hot air $(\mathrm{n}=12,12.4 \%)$ were also common self-reported triggers in the work environment.

The mean SNOT-22 score amongst patients with symptoms that worsened at work was significantly higher compared to the scores amongst non-work-related patients $(39.42( \pm \mathrm{SD}$ $16.7)$ and $32.05( \pm$ SD 18.2) (Figure 1). We identified a statistically significant difference between these groups in the mean values of five items (Figure 1). In addition, the mean values for the SNOT-22 subscales significantly differed between these groups in terms of nasal symptoms $(P=0.029)$ and especially in terms of otologic/facial pain $(P=0.00017)$. Ssleep and emotional symptom subdomains did not differ statistically between these patient groups. However, the mean 15D score did not differ between those whose symptoms worsened at work and those whose symptoms did not (Figure 2).

Altogether $43(24.3 \%)$ patients were exposed to specific occupational agents at their work. More specifically, 38 patients $(21.5 \%)$ were exposed to a LMW agent, 9 patients (5.1\%) to a HMW agent and 4 patients $(2.3 \%)$ were exposed to both HMW and LMW agents or irritants. We found no age difference between the occupationally exposed and nonexposed patients $(\mathrm{P}=0.290)$, although exposed patients were more often men and manual laborers $(P<0.05)$. The mean SNOT-22 scores amongst exposed (37.2) and nonexposed patients (35.9) did not differ significantly $(P=0.659)$. However, in the mean values for three items, occupationally exposed patients fared worse than nonexposed patients: a loss of smell or taste $(P=0.004)$, cough $(P=0.035)$ and post-nasal discharge $(P=0.036)$. We found no statistically significant difference between exposed and nonexposed patients in the SNOT22 subscales. The mean 15D score did not differ between the exposed and nonexposed patients $(0.867$ and 0.885 , respectively, $P=0.320$ ).

Absenteeism due to rhinologic disease during the preceding year was reported by $59.9 \%$ of patients. The mean length of absence from work was 15.4 days $( \pm$ SD 25.919 , range $0-190$ days), of which 7.7 days ( \pm SD 14.626, range $0-120$ days) were due to rhinologic disease. 
4.0
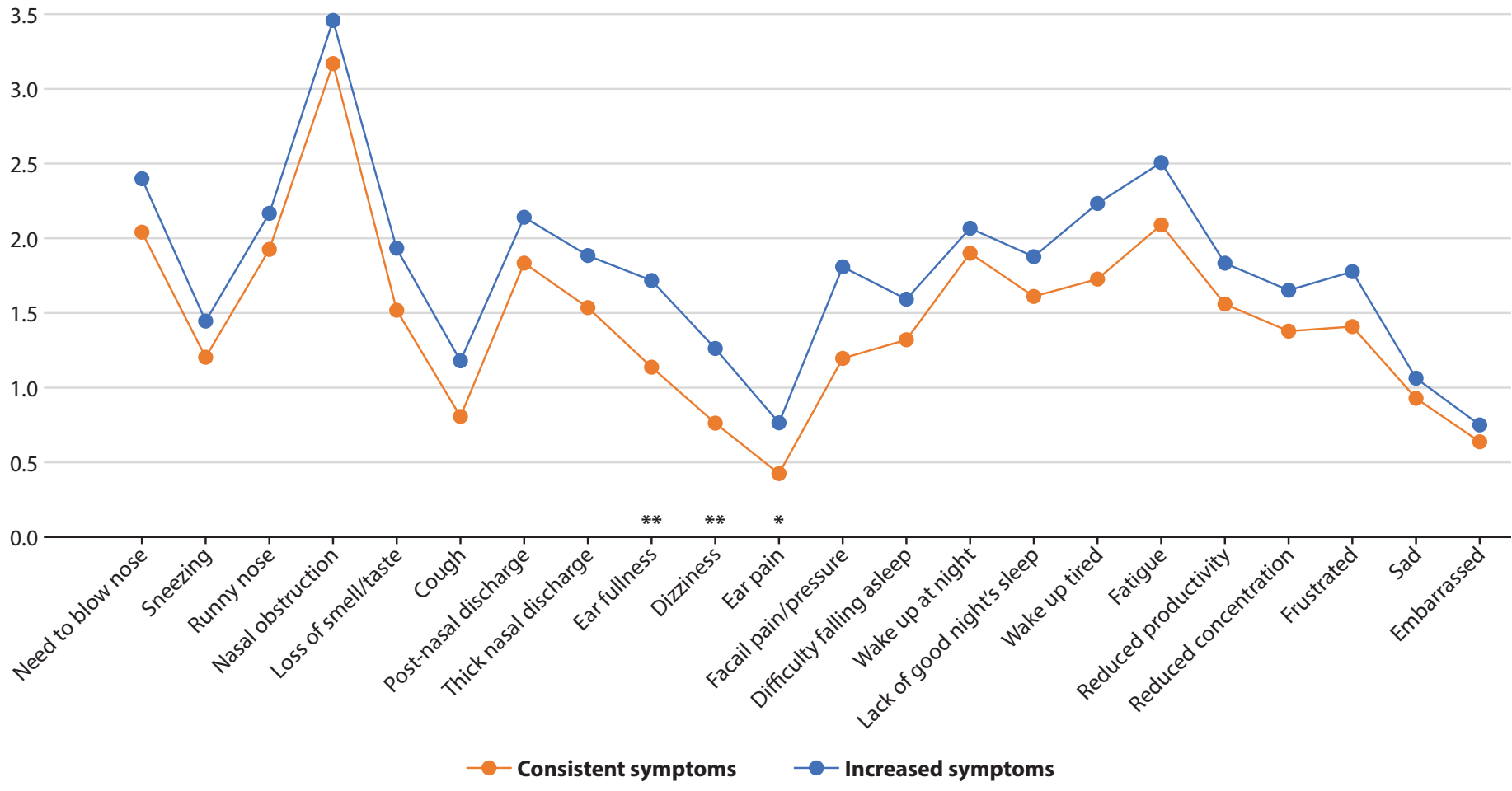

Figure 1. SNOT-22 profile amongst patients with worsening symptoms at work and amongst patients with consistent symptoms at work and during free-time (mean SNOT-22 values: 39.422 and $32.05 ; P=0.0165$ ). ${ }^{\star} P<0.05,{ }^{\star \star} P<0.01$

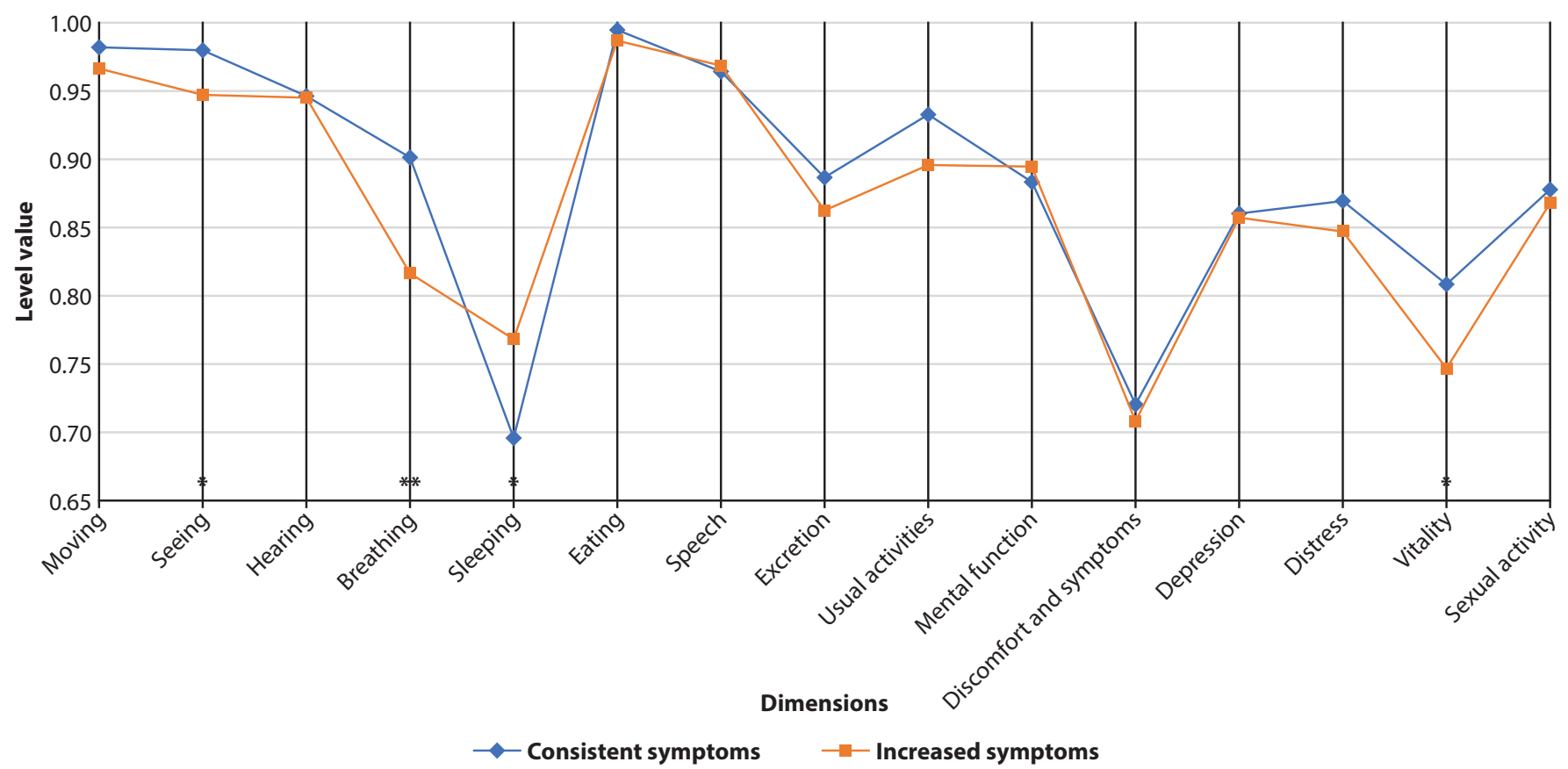

Figure 2. Mean 15D profile amongst patients with worsening symptoms at work $(\mathrm{n}=101)$ and amongst patients with consistent symptoms at work and during free-time $(n=66)$. Mean $15 \mathrm{D}$ score for patients with worsening symptoms was 0.874 , whilst that for patients with consistent symptoms was $0.891(P=0.232) .{ }^{\star} P<0.05,{ }^{\star *} P<0.01$ 


\section{Discussion}

In this prospective study of unselected, mostly upper-level employed, rhinology patients, the majority, about $60 \%$, of patients reported exacerbated symptoms at work. Patients whose symptoms worsened at work received significantly higher SNOT-22 scores, whilst the generic HRQoL were similar to patients without non-work-related exacerbation. Most of our patients reported unspecific triggers, and occupational-specific exposures were present in only a quarter of patients. Work absenteeism due to rhinologic diseases was markedly elevated. These findings are best applicable for unselected secondary/ tertiary care clinic patients.

To our knowledge, this is the first study on the impact of work on employed rhinologic clinic patients' symptoms and HRQoL. The combination of both disease-specific and generic HRQoL tools granted us thorough understanding about the HRQoL of nasal patients. Our patients underwent clinical ear, nose and throat examination, tests and radiological examination, if needed, in a tertiary rhinologic clinic. Occupational exposures were assessed by a specialized occupational hygienist based on the individual patient's occupation, job description and patient-reported exposures.

Nasal symptom exacerbation was reported by most of our patients. Similar studies have not been reported in rhinologic clinic patients. However, findings of symptom worsening at workplaces are quite common. Forty-two \% of Finnish men and $25 \%$ of women reported some harm due to dust at the workplace. ${ }^{19}$ In a Belgian workforce study work-related rhinitis was found in 33\%.9 In this study work-related nasal symptoms were associated with significantly lower HRQoL according to SNOT-22, when compared to non-work -related rhinologic symptoms. Although the populations are not comparable, the result is in line with the Belgian workforce study which has previously reported higher impact of work-related rhinitis compared to non-work -related rhinitis on HRQOL. ${ }^{9}$

In this study the frequency of asthma, allergies and smoking were not statistically different between patients with or without work-related exacerbation. This can be explained by the small number of these patients in our study sample. In previous studies, noninfectious rhinitis and CRS were significantly affected by exposure to airway irritants, but the effect was influenced by smoking, an allergy, asthma and gender. ${ }^{6,8,9,20}$ Female gender has been associated with indoor air-related symptoms, ${ }^{21,22}$ but we did not detect this gender gap in our patient sample.

The most commonly reported triggers amongst our rhinology patients at work included unspecified triggers and nonspecific occupational exposures. Air quality was affected by a variety of unspecified factors, including ventilation, dust, humidity, temperature or a draft, factors which could also impair comfort and cause symptoms. The most common complaints and symptoms related to the indoor environment in Finland were dry air, stale air and dust, listed in a 2018 workers' query. ${ }^{23}$ In a European $(\mathrm{n}=7441)$ office worker study, $37 \%$ reported indoor air quality problems and 50\% reported suffering from a building-related symptom during the previous month. ${ }^{24}$ The findings from these studies are not directly comparable to our results, however, since the patients in our cohort were asked more specifically which work-related indoor environment factors worsened their rhinologic symptoms. However, the distribution of the triggers in our patients was quite similar. Interestingly these triggers are similar to those described to trigger unspecific nasal hyperreactivity in the literature. In line with this, the prevalence of work-exacerbated rhinitis in our sample resembles the prevalence of nasal hyperreactivity in rhinitis. ${ }^{25}$

In addition, the patients here estimated their overall sick leave periods as totaling on average 15.4 days during the previous year, of which they estimated that rhinologic causes resulted in an average of 7.7 days of self-certified sickness. These estimates are rather high compared to the average number of overall self-reported sickness absences, totaling 8.9 days per year per employee in Finland. Since socioeconomic class influences sickness absences and given that our patients had a higher-than-average socioeconomic class, ${ }^{26}$ the average that rhinologic causes resulted might be even higher. Our results compare favorably to a previous study amongst patients with CRS, in which the mean absenteeism scores caused by sinus problems varied from somewhere between 8 and 14 days per year. ${ }^{27}$ Rhinitis costs to society have been previously shown to primarily result from the impairment of work productivity, ${ }^{28}$ whilst the indirect costs (i.e., work absenteeism) should also be taken into account. According to our study, a similar disease burden as found in CRS and rhinitis also appears to be likely in other rhinologic clinic patients and will need further investigation between patient groups. In our study, four-fifths of patients in the rhinology outpatient clinic were in working life. Therefore, it is important to pay attention to the significant impact of nasal diseases, especially on the working age population. Rhinologic diseases are associated with substantial work productivity loss due to absenteeism among patients who come to rhinologic consultation. The productivity impact and absenteeism due to rhinologic diseases highlight the importance of disease management.

Our study has some potential limiations. In the present study, We did not collect data of depressed mood of the patients although depression has been associated with lost productivity in patients with CRS and AR. ${ }^{28-30}$ Patients suspected of having a specific occupational disease are recommended to be referred to occupational health clinics. Our study patients had fewer manual laborers compared to the average Finnish population, thereby likely reducing the number of occupational exposures in our study. However, it seems that occupational exposures had not been left unnoticed when referring patients to our clinic. A so-called healthy worker bias, whereby currently employed healthier individuals are more likely to be working, is a possible limitation to our study. ${ }^{31}$ Survivor bias can have decreased the HRQoL effect found, since workers with work-related-rhinitis can be a reason to change jobs to such which does not worsen their symptoms. ${ }^{9}$ Although SNOT-22 questionnaire was initially validated in CRS we used it as a HRQoL tool in our study as done successfully in numerous rhinitis studies previously. As occupational exposures are typically perennial, possible bias caused by the lack of conjunctivitis questions typical to seasonal allergic reactions is probably quite limited. The sample size in our study was moderately small without a control group. 
The estimate for the response rate, $46 \%$, was fairly low, but it is typical in postal questionnaire studies.

\section{Conclusions}

In this study amongst various rhinologic patients, the work-related aggravation of patients' nasal symptoms was very common and seemed to be related to the severity of rhinologic disease, and not to specific occupational exposure. This is well in line with previous studies. The primary triggers at work remained nonspecific, described nasal hyperreactivity triggers in our patients, but the possibility of specific occupational disease should be kept in mind in every patient evaluation. Despite a lower specific HRQoL in relation to work amongst most patients, generic HRQoL was not affected. Finally, work absenteeism amongst rhinology clinic patients was substantial.

\section{Acknowledgements}

We thank all the patients who participated in this study, specialized occupational hygienist Katriina Ylinen for assistance in the classification of exposures, professional statistician Timo Pessi for carrying out the statistical analyses, and Vanessa Fuller for revising the manuscript.

\section{Conflict of interest}

Harri Sintonen is the developer of the $15 \mathrm{D}$ instrument. The other authors declare that there is no conflict of interest.

\section{Funding}

The study was supported in part by research grants from Helsinki University Hospital Research Funds, Paulo Foundation, the Tampere Tuberculosis Foundation and the Foundation of the Finnish Anti-Tuberculosis Association.

\section{Authors' contributions}

- Conceptualization: All

- Methodology: MY

- Formal analysis and investigation: MY, LA, PV

- Writing: MY, LA, PV

- Writing and editing: MY, LA, PV, HS, RPR, MH

- Supervision: LA, PV

\section{References}

1. Bousquet J, Van Cauwenberge P, Khaltaev N, Aria Workshop G, World Health O. Allergic rhinitis and its impact on asthma. J Allergy Clin Immunol. 2001;108(5 Suppl):S147-334.

2. Haahtela T, von Hertzen L, Makela M, Hannuksela M, Grp APW. Finnish Allergy Programme 2008-2018 - time to act and change the course. Allergy. 2008;63(6):634-45.

3. Hastan D, Fokkens WJ, Bachert C, Newson RB, Bislimovska J, Bockelbrink A, et al. Chronic rhinosinusitis in Europe--an underestimated disease. A GA(2)LEN study. Allergy. 2011;66(9):1216-23.

4. Hox V, Delrue S, Scheers H, Adams E, Keirsbilck S, Jorissen M, et al. Negative impact of occupational exposure on surgical outcome in patients with rhinosinusitis. Allergy. 2012;67(4):560-5.

5. Hox V, Steelant B, Fokkens W, Nemery B, Hellings PW. Occupational upper airway disease: how work affects the nose. Allergy. 2014;69(3):282-91.
6. Thilsing T, Rasmussen J, Lange B, Kjeldsen AD, Al-Kalemji A, Baelum J. Chronic rhinosinusitis and occupational risk factors among 20- to 75-year-old Danes-A GA(2) LEN-based study. Am J Ind Med. 2012; 55(11):1037-43.

7. Kaukiainen A, Martikainen R, Riala R, Reijula K, Tammilehto L. Work tasks, chemical exposure and respiratory health in construction painting. Am J Ind Med. 2008;51(1):1-8.

8. Hellgren J, Lillienberg L, Jarlstedt J, Karlsson G, Toren K. Population-based study of non-infectious rhinitis in relation to occupational exposure, age, sex, and smoking. Am J Ind Med. 2002;42(1):23-8.

9. Vandenplas O, Suarthana E, Rifflart C, Lemière C, Le Moual N, Bousquet J. The Impact of Work-Related Rhinitis on Quality of Life and Work Productivity: A General Workforce-Based Survey. J Allergy Clin Immunol Pract. 2020;8(5):1583-91.e5.

10. Lange B, Thilsing T, Baelum J, Kjeldsen AD. The Sinonasal Outcome Test 22 score in persons without chronic rhinosinusitis. Clin Otolaryngol. 2016;41(2):127-30.

11. Hopkins C, Surda P, Bast F, Hettige R, Walker A, Hellings PW. Prevention of chronic rhinosinusitis. Rhinology. 2018;56(4):307-15.

12. EAACI Task Force on Occupational Rhinitis, Moscato G, Vandenplas O, et al. Occupational rhinitis. Allergy. 2008;63(8):969-80.

13. Fokkens WJ, Lund VJ, Mullol J, Bachert C, Alobid I, Baroody F, et al. EPOS 2012: European position paper on rhinosinusitis and nasal polyps 2012. A summary for otorhinolaryngologists. Rhinology. 2012;50(1):1-12.

14. Hytönen M, Hammarén-Malmi S, Myller J, Mäkelä M, Penttilä E, Pessi $\mathrm{T}$, et al. Tautikohtaisen elämänlaatumittarin validointi - esimerkkinä nenä- ja sivuontelotautikohtainen SNOT-22-mittari. Duodecim. 2017; 133(13-14):1317-25. Finnish.

15. Hopkins C, Gillett S, Slack R, Lund VJ, Browne JP. Psychometric validity of the 22-item Sinonasal Outcome Test. Clin Otolaryngol. 2009;34(5):447-54.

16. Feng AL, Wesely NC, Hoehle LP, Phillips KM, Yamasaki A, Campbell AP, et al. A validated model for the 22-item Sino-Nasal Outcome Test subdomain structure in chronic rhinosinusitis. Int Forum Allergy Rhinol. 2017;7(12):1140-8.

17. Statistics Finland [Internet]. Helsinki: Statistics Finland; c2021 [cited 2021 May 1]. Classification of Socio-economic Groups 1989; [about 1 screen]. Available from: http://www.tilastokeskus.fi/meta/luokitukset/sosioekon_ asema/001-1989/index_en.html

18. Alatalkkari S, Rautesalo T, Laakkonen A, Rautiainen M, editors. Statistical Yearbook of the Social Insurance Institution Finland 2014 [Internet]. Helsinki: Publisher: KELA [cited 2021 May 1]. 482 p. Available from: https://helda.helsinki.fi/bitstream/handle/10138/158254/Kelan_ tilastollinen_vuosikirja_2014.pdf?sequence $=1$ \&isAllowed $=y$

19. Aromaa A, Koskinen S, editors. Suomalaisten työ, työkyky ja terveys 2000-luvun alkaessa, raportti 11/2010. Helsinki: The Finnish Institute for Health and Welfare; 2010. Finnish

20. Hisinger-Mölkänen $H$, Piirilä $P$, Haahtela T, Sovijärvi A, Pallasaho P. Smoking, environmental tobacco smoke and occupational irritants increase the risk of chronic rhinitis. The World Allergy Organization journal. 2018;11(1):6.

21. Runeson R, Wahlstedt K, Wieslander G, Norback D. Personal and psychosocial factors and symptoms compatible with sick building syndrome in the Swedish workforce. Indoor Air. 2006;16(6):445-53.

22. Brasche S, Bullinger M, Morfeld M, Gebhardt HJ, Bischof W. Why do women suffer from sick building syndrome more often than men? --subjective higher sensitivity versus objective causes. Indoor Air. 2001; 11(4):217-22.

23. Kauppinen T, Mattila-Holappa, P., Perkiö-Mäkelä, M., Saalo, Anja., et al. Työ ja terveys Suomessa: Finnish Institute of Occupational Health; 2012.

24. Bluyssen PM, Roda C, Mandin C, Fossati S, Carrer P, de Kluizenaar Y, et al. Self-reported health and comfort in 'modern' office buildings: first results from the European OFFICAIR study. Indoor Air. 2016;26(2):298-317.

25. Van Gerven L, Steelant B, Hellings PW. Nasal hyperreactivity in rhinitis: A diagnostic and therapeutic challenge. Allergy. 2018;73(9):1784-91.

26. Kristensen TR, Jensen SM, Kreiner S, Mikkelsen S. Socioeconomic status and duration and pattern of sickness absence. A 1-year follow-up study of 2331 hospital employees. BMC Public Health. 2010;10:643.

27. Sahlstrand-Johnson P, Ohlsson B, Von Buchwald C, Jannert M, Ahlner -Elmqvist M. A multi-centre study on quality of life and absenteeism in patients with CRS referred for endoscopic surgery. Rhinology. 2011;49(4): $420-8$. 
28. Vandenplas O, Vinnikov D, Blanc PD, Agache I, Bachert C, Bewick M, et al. Impact of Rhinitis on Work Productivity: A Systematic Review. J Allergy Clin Immunol Pract. 2018;6(4):1274-86.e9.

29. Campbell AP, Hoehle LP, Phillips KM, Caradonna DS, Gray ST, Sedaghat AR. Depressed mood is associated with loss of productivity in allergic rhinitis. Allergy. 2018;73(5):1141-4.
30. Campbell AP, Phillips KM, Hoehle LP, Feng AL, Bergmark RW, Caradonna DS, et al. Depression symptoms and lost productivity in chronic rhinosinusitis. Ann Allergy Asthma Immunol. 2017;118(3):286-9.

31. Johnson CY, Rocheleau CM, Lawson CC, Grajewski B, Howards PP. Factors affecting workforce participation and healthy worker biases in U.S. women and men. Ann Epidemiol. 2017;27(9):558-62.e2. 